\title{
Chinese teachers' perceptions of an online teacher course and its results
}

\author{
Nan $\mathrm{Li}^{1}$ (D) $\cdot$ Ruurd Taconis ${ }^{1} \cdot$ Perry den Brok ${ }^{2}$
}

Received: 24 December 2018 / Accepted: 31 January 2021 / Published online: 29 April 2021

(C) The Author(s) 2021

\begin{abstract}
We investigated teachers' perceptions of an online inservice teacher course in China and its outcomes, as well as connections between these two types of perceptions. Data were collected from a sample of 251 teachers following a course on Information and Communication Technology in education using a questionnaire survey and interviews. Teachers were generally satisfied with the setup and content of the course, but considered that interaction during training and motivation were not optimal. A correlation analysis showed that teachers' perceptions of the course were significantly and positively related to their perceptions of training outcomes. Regression analyses revealed that the connection of training content with teachers' daily practice contributed most positively to teachers' perceptions of the training outcomes. Suggestions for optimizing online inservice teacher courses are provided.
\end{abstract}

Keywords Teacher perceptions $\cdot$ Teacher training $\cdot$ Training with online platform

\section{Introduction}

Teachers' lifelong learning has become a worldwide necessity, partly because of rapid changes in education such as the use of multi-media facilities in classrooms and digital teaching materials (Choi 2013; Finsterwald et al. 2013; Robinson 2008). With the development of Information and Communication Technology (ICT), online learning environments have been introduced in many countries to provide teachers with wider and more-flexible learning opportunities (Jung 2001). Online courses for inservice teachers have obvious advantages in regions that have to deal with training large numbers of teachers and that

Nan Li

linantue@gmail.com

Perry den Brok

perry.denbrok@wur.nl

1 Eindhoven School of Education, Eindhoven University of Technology, De Zaale, 5600MB Eindhoven, The Netherlands

2 Education and Learning Sciences, Department of Social Sciences, Wageningen University, Hollandseweg 1, 6706KN Wageningen, The Netherlands 
have an uneven distribution of economic development and training resources, such as flexibility and the ability to deal with large numbers of participants (Jung 2005a).

\section{Learning environment}

Previous research has shown that the quality of the learning environment is a significant determinant of student learning (Dorman 2001). Studies have provided consistent evidence that learning achievement is associated with learners' perceptions of the learning environment (Bonem et al. 2020). Most of the existing studies focused on the students' perceptions of the classroom environment (Khalil and Saar 2009; Allen and Fraser 2007), but there have been only a few studies of learners' perceptions of online learning environments (e.g., Earle and Fraser 2017).

In addition, most research on the context of teacher training has focused on the perceptions of students and preservice teachers rather than inservice teachers as learners (Chandra and Fisher 2009; Magen-Nagar and Steinberger 2017; Seet and Quek 2010). Many studies have involved the correlation between students' perceptions of the learning environment and their learning outcomes. Gilbert et al. (2014) examined the relationship between middle-school students' perceptions of the classroom environment and their motivation and learning achievement. Webster and Fisher (2003) reported that the school-level environment was linked to student outcomes. However, the correlation between perceptions of the learning environment and learning outcomes remains largely unclear in inservice teacher courses. In the present study, we contributed to these gaps by investigating the perceptions of inservice teachers (as learners) of an online environment and by exploring associations between teachers' perceptions of the online learning environment and learning outcomes.

\section{Research context}

In order to resolve the large shortage of qualified teachers in China, the Ministry of Education and the Ministry of Finance of the Chinese government initiated the National Teacher Training Project (NTTP) in 2010. The NTTP implements face-to-face courses as well as online courses. More than 9 million teachers have been trained in the NTTP since 2010, with about $85 \%$ of the teachers trained via online programs and around $95 \%$ from rural areas (http://www.moe.gov.cn/jyb_xxgk/xxgk_jyta/jyta_jiaoshisi/201611/t20161107_ 287919.html). However, more than $80 \%$ of existing empirical research on teacher courses in NTTP focused on face-to-face courses. Although these online teacher courses in China have been supported by budgets of millions of euros, little research has been conducted into their effectiveness and these few studies mostly excluded teachers' perceptions $(\mathrm{Qu}$ 2012; Zhang 2012).

Using ICT in teacher training can take different forms (Jung 2005b), including radio, television, video, DVD, telephone, satellite systems, computer and network hardware and software, as well as equipment and services associated with these technologies such as videoconferencing and electronic mail (UNESCO 2002). Online teacher courses in NTTP use an online learning platform (learning management system: LMS) as the core technology for delivering teacher training. In the study presented in this paper, we focus on investigating training with these online platforms.

Despite the large number of online teacher courses implemented in China, the effectiveness of these programs has hardly been investigated. Furthermore, few studies have 
investigated courses from the perspective of the participating teachers via their perceptions, both in China and internationally. The present study filled this gap and contributed to optimizing online teacher courses via the use of teacher perceptions.

Characteristics of successful teacher professional development and training with online platform have been widely agreed upon and applied in Western research (Garet and Porter 2001; Hunzicker 2011; Penuel et al. 2007), but less research exists about their suitability for non-Western cultures, such as the Confucian Chinese culture. Therefore, in this study, we also investigated whether existing theories about teacher professional development and training with online platforms also apply to the Chinese context.

Chinese culture is different from that of Western countries. It is likely that the characteristics of Chinese context influence the implementation and teachers' perceptions of courses. According to Hofstede (2011) cultural dimension studies, China has a higher score on power-distance than Western countries such the UK or US, which means that people have higher expectations and acceptance of the unequally-distributed power. China also has a lower score on individualism, which indicates that people act in the interests of the group more than of themselves (Hofstede 2011). In online teacher courses, this might come to the fore in the (perceived or expected) distance between trainer and teacher, in compulsory and collective participation in a course, and possibly in lower intrinsic motivation. Instructors are authority figures in Chinese culture (House 2000). Chinese are less likely to challenge others as it is disrespectful and could cause them to lose face (Kennedy 2002).

The authors' earlier, small-scale exploratory study analyzed government policy documents, course documents and web-platform information (Li 2020) from five online courses. Interviews with ten teachers and two tutors were collected and analyzed to obtain an overall image of online teacher courses in NTTP. The previous study showed that most characteristics of successful teacher professional development and training with online platforms in the Western literature were also implemented and appreciated in China. However, some characteristics such as active interaction, adapting the course to a specific group of teachers, and focusing on teachers' daily practice were less emphasized. For instance, there was no direct interaction between teachers and trainers, courses were conducted for a group of teachers from one region while the training content did not align with the textbooks used in that region, there were many theoretical lectures rather than practical content, etc. This raised questions about how teachers perceived their training outcomes and how this correlated with their perceptions of the course. The present study focused on one online teacher course in China and involved evaluating teachers' perceptions of the course, their perceptions of the training outcomes, and the correlation between these variables.

\section{Theoretical framework}

In this section, the major concepts behind this study are reviewed. To investigate course perceptions and outcomes thoroughly, the four-level evaluation model by Kirkpatrick (1970), including reaction, learning, behavior, and result was used. According to Kirkpatrick (1970, 2005), reaction can be defined as the extent to which teachers like a course; learning refers to the principles, facts, and techniques that are understood and absorbed by teachers; behavior is the extent to which teachers apply the learning and change their behavior; and result refers to the effect of training expressed in the improved performance of the teacher and which reflects the progress of students. 
In order to gain comprehensive insight into the effects of a course, Kirkpatrick recommends gathering data at the four levels, as well as learner outcomes observed after a considerable period of time (Frye and Hemmer 2012). However, it is widely agreed that the evaluation of the learning, behavior and result levels are more difficult than that of reaction, because training is often not the only causal factor of change (Tamkin et al. 2002). Furthermore, assessing the training outcomes at the behavior and result levels typically requires a long-term or longitudinal research design. This study focused on teachers' perceptions (reaction) towards different aspects of the course, their perception of the training outcomes a few months after the end of the course (learning, behavior, and results), and the correlation between these variables.

\section{Reaction}

Mapping reaction can be focused on different elements. In this study, reaction was conceptualized as teachers' perceptions of the course in terms of the context, experience, and course setup (Chandra and Fisher 2009; Long et al. 2008). Context refers to the external factors that might affect course success. Experience focuses on teachers' reflections of their own performance during training. Course setup refers to teachers' perceived characteristics of the course itself. Ideally, online courses should follow the theoretically-known characteristics of successful teacher professional development. The online environment enables the course with new functions (e.g. asychronized text-based discussion) and has certain requirements (e.g. a well-organized web platform) to ensure learning effectiveness.

To understand teachers' reactions toward the course, characteristics of successful teacher professional development (Garet and Porter 2001; Guskey 2002; Hunzicker 2011; Penuel et al. 2007; van Driel et al. 2012) and effective training with online platforms (Cox et al. 2003; Goktas et al. 2008; Jung 2001, 2005a) from the literature were summarized and included in this study in the form of eight aspects, namely: external support, motivation, interaction, people, platform, structure, content, and connection.

External support reflects the context, motivation and interaction represent the experience, and the other five aspects embody the course setup. These 8 aspects cover the criteria of successful teacher professional development and effective training with online platform derived from the literature. These correspond to the design features of online teacher courses in NTTP and were also used to design the questionnaire used in this study.

External support refers to the support that teachers get for participating in a course from their principal, colleagues, and family. When teachers feel supported externally, they are more willing to take professional risks by trying new things (Hunzicker 2011). Previous research has also shown that support from home, peers (Mumtaz 2000), and school (Ertmer and Ottenbreit-Leftwich 2010) is significant for successful teacher professional development, especially when ICT is the topic concerned.

Teachers' motivation to learn during training is regarded as vital for effectiveness in terms of both teacher professional development and training with online platforms. In our previous study, teachers' motivation was found to be weak. The ARCS model, which uses the four factors of attention, relevance, confidence, and satisfaction to describe motivation (Keller 1987, 2000), was adopted for investigating teachers' motivation during training in this study. Attention refers to whether a teacher is interested in the learning material and is concentrating on learning. Relevance indicates whether the learner feels that the learning is useful or valuable. In previous studies, learners' perceived usefulness of an online course was positively correlated with their satisfaction (Arbaugh 2000; Cox 2000). Confidence 
refers to teachers' expectations of success. Sun et al. (2008) reported that learners' confidence in their performance in online learning was positively correlated with their course satisfaction. Effort refers to the extent to which teachers put effort into the course, even beyond is required.

It is widely accepted that frequent and effective interaction is a key factor for successful educational activities (van Bruggen 2005). Teachers' perceptions of the frequency and effectiveness of their interaction with the trainer, tutor, and other teachers were investigated in this study. Arbaugh (2000) reported that students' interaction with class participants affected learners' satisfaction. In another study, learners who perceived the student-instructor interactions positively were more satisfied in a webbased course (Hong 2002).

Characteristics concerning the course can be summarized into several aspects. Firstly, the performance of people (referring to trainers and tutors in the course investigated in this study) plays a role in teachers' perceptions of the course. Tu and Mcissac (2010) reported significant positive correlations between learners' perception of trainers and their satisfaction with an online course.

Being the environment of teachers' learning, the online platform reflects the cyber characteristics for effective training with that platform. Sun et al. (2008) indicated that, if learners perceive the online learning platform as being easy to use, they are more satisfied with the online course. In the present study, teachers' perceptions of the online platform included the navigation system, website layout, user manual, and help system.

The structure of the course is the third important course feature in the present study. This includes whether the course is systematically designed, offers various of learning activities, has clear objectives and a comprehensive evaluation plan, and is consistent over different activities The content quality of online training courses is also considered a significant factor in learner satisfaction (Piccoli et al. 2001; Sun et al. 2008). In our previous study, interviewed teachers attributed their course satisfaction mainly to the connection of the content to their daily job tasks. Connection here thus refers to the extent to which teachers feel that the content is connected with the situations with which they deal in daily practice, and the extent to which they feel that the content is applicable in their classroom.

\section{Learning, behavior and results}

An important part of any course evaluation is assessing whether course learning objectives are met. Training outcomes at the learning level are distinguished in terms of increased knowledge (understanding the concepts, principles and techniques being taught), developed skills, and changed attitudes (Kirkpatrick and Kirkpatrick 2005). In this study, teachers were expected to expand their knowledge of teaching with ICT, learn and practice ICT skills to be used in teaching, and develop a more-positive attitude towards teaching with ICT.

The level of behavior refers to actual on-the-job performance (Omar et al. 2009; Praslova 2010; Strother 2002). In the present study, teachers' perceptions of training outcomes at the behavior level included teachers' perceived changes in classroom practice after the course.

The results level is both highly desirable and very difficult to evaluate (Praslova 2010), not only because collecting data for this level is time-consuming and costly 
(Rajeev et al. 2009), but also because environmental constraints greatly influence outcomes at the result level (Praslova 2010). In the present study, teachers' perceptions of training outcomes at the results level refer to perceived changes in their students' learning outcomes.

\section{Research questions}

The objective of the current study was to investigate an online course for secondary school teachers. The focus was how teachers experienced and perceived this course, and how it influenced their perceptions of the training outcomes. To this end, three specific research questions were formulated:

1. How did teachers perceive the online course in terms of context, experience, and course set-up features?

2. How did teachers perceive the training outcomes at the level of learning, behavior, and results?

3. What is the relationship between teachers' perceptions of the course and their perceived training outcomes?

Table 1 Training content

\begin{tabular}{ll}
\hline Section & Module \\
\hline Preparation & Module 1: Preparation (1 week) \\
& Module instructions \\
& Pre-assessment and learning plan \\
Theoretical & Module 2: Teacher professional develop- \\
& ment with ICT (2 weeks) \\
& Module instructions \\
Interpretation of The Standards of \\
Teachers' Competence of Teaching \\
with ICT \\
Assignment \\
Module 3: Teaching with ICT (4 weeks) \\
Module instructions \\
Optimizing teaching with ICT \\
Transforming learning with ICT \\
Assignment \\
Module 4: Course evaluation (2 weeks) \\
Module instructions \\
Learning report \\
Epplication in classroom \\
Questionnaire survey
\end{tabular}




\section{Methods}

\section{The course investigated in this study}

The course investigated in the present study was an online inservice teacher course for secondary school teachers of all subjects working in the Hainan province. The online training had a duration of three months. Six schools in the Wenchang district were selected by the local educational department to participate. Nearly all subject teachers in these six schools took part in this course. The training theme was 'improving teachers' competences of teaching with ICT'. A description of the training content can be found in Table 1. Learning activities included watching pre-recorded video lectures, participating in online asynchronous discussions, and completing individual assignments, reading newsletters, reviewing other teachers' assignments, etc. Teachers from different subjects followed the same course structure but had subject-specific content in modules 2 and 3 .

\section{Sample}

The selected course reflected the mainstream of online teacher courses in China in recent years and had 3184 teachers, 251 of whom were chosen as the sample of this study. We chose these 251 teachers because they worked in six schools located in one district. These schools are managed by the one local educational authority, which minimized the possible difference caused by local development and educational culture. A questionnaire survey was used three months after the end of online training to collect teachers' perceptions. Hard copies of the questionnaire were handed to each teacher. In the end, 224 questionnaires were collected with a response rate was $89.2 \%$. Table 2 describes the survey and interview samples (see further below). Hainan is one of the underdeveloped provinces in China. According to an inspection of the ICT equipment in school, these six schools had one to five multi-media classrooms, although most of these were not frequently used. School C had no ICT equipment in the classroom. Classrooms in other schools were partly equipped with computers, electronic whiteboards, and projectors, but without proper maintenance. Teachers mainly shared computers in offices with colleagues teaching the same subject.

According to the background section in the questionnaire survey, the gender breakdown was $51.8 \%$ male and $47.8 \%$ female. Teachers' ages ranged from 24 to 59 years (Mean $=38.54, \mathrm{SD}=7.46$ ) and teaching experience ranged from 1 to 41 years $(\mathrm{Mean}=16.15, \mathrm{SD}=8.48)$. The distribution of teaching subjects was roughly in line with

Table 2 Schools and interviewees

\begin{tabular}{lllll}
\hline School & $\begin{array}{l}\text { Number of } \\
\text { teachers }\end{array}$ & $\begin{array}{l}\text { Interviewee } \\
\text { code }\end{array}$ & Gender & Subject \\
\hline A & 54 & A1 & M & Physics \\
& & A2 & F & Biology \\
B & 44 & B1 & M & Physics \\
C & 21 & C1 & M & Chemistry \\
D & 44 & D1 & F & Math \\
E & 38 & E1 & M & Math \\
F & 50 & F1 & M & Math \\
& & F2 & M & ICT \\
\hline
\end{tabular}


the number of teachers in each subject in secondary schools in China. Chinese teachers, mathematic teachers, and English teachers accounted for $49.6 \%$ of all teachers. About 82.6\% of the teachers had a Bachelor's degree, $15.6 \%$ held an Associate Bachelor's degree or lower degrees, and no teacher had a Master's degree or above. Approximately $93.8 \%$ of the teachers had a personal computer, and $79.9 \%$ had internet connection at home. Therefore, teachers might not entirely rely on the computers in school to participate in their training. About $77.7 \%$ of teachers were using a smartphone, while $24.1 \%$ of teachers had a tablet.

Eight teachers were selected for an interview (see Table 2) based on two rules: at least one interviewee should be present from each school, and preferably scientific-domain teachers (mathematics, physics, chemistry, biology, and ICT) were selected in order to keep influences due to school subject to a minimum. At the same time, science teachers are expected to use ICT to a large degree, because the content of their subject often involves the need to use software.

\section{Questionnaire survey}

The questionnaire used in this study consisted of six sections. Apart from the background information section and an open-end questions section about further suggestions for

Table 3 Scales and Cronbach's alpha coefficients

\begin{tabular}{llll}
\hline Section & Scale & $\begin{array}{l}\text { Number of } \\
\text { items }\end{array}$ & $\begin{array}{l}\text { Cron- } \\
\text { bach's } \\
\text { alpha }\end{array}$ \\
\hline Reaction & External support $^{\mathrm{a}}$ & 3 & .90 \\
& Attention $^{\mathrm{b}}$ & 3 & .84 \\
& Relevance $^{\mathrm{b}}$ & 3 & .86 \\
& Confidence $^{\mathrm{b}}$ & 3 & .76 \\
& Effort $^{\mathrm{b}}$ & 3 & .79 \\
& Interaction $^{\mathrm{c}}$ & 6 & .92 \\
& People $^{\mathrm{d}}$ & 2 & .95 \\
& Platform $^{\mathrm{d}}$ & 8 & .96 \\
& Structure $^{\mathrm{d}}$ & 10 & .97 \\
& Content $^{\mathrm{d}}$ & 2 & .88 \\
& Connection $^{\mathrm{d}}$ & 7 & .93 \\
Learning & Learning $^{\mathrm{b}}$ & 9 & .94 \\
Behavior & Behavior $^{\mathrm{b}}$ & 6 & .93 \\
Results & Results $^{\mathrm{b}}$ & 4 & .93 \\
\hline
\end{tabular}

${ }^{\text {a }}$ These items have options from 1 to 5 represents strongly discouraged to strongly support

${ }^{\mathrm{b}}$ These items have options from 1 to 5 represents strongly disagree to strongly agree

${ }^{\mathrm{c}}$ These items have options from 1 to 5 represents very rare to very frequent

${ }^{\mathrm{d}}$ These items have options from 1 to 5 represents very bad to excellent 
improvement of the online teacher course, the other four sections of questionnaire (shown in Table 3) corresponded to the four levels of Kirkpatrick's evaluation model.

The 11 scales in the reaction section correspond to the characteristics of successful teacher professional development and training with online platforms, and reflected teachers' perceptions of the course. The 11 scales are external support, attention, relevance, confidence, effort, interaction, people, platform, structure, content, and connection. The scales of learning, behavior, and result reflect teachers' perceptions of the training outcomes. When possible, we used items and scales (e.g. items in scale attention, relevance, confidence, and effort) from existing studies (Keller 2000). Other items or scales were designed by the authors of this manuscript according to the literature around effective teacher professional development and training with online platform as stated in the theoretical framework section.

The questionnaire was originally designed in English (see Appendix) and then reviewed by two senior researchers within our research institute to ensure face validity and construct validity (Trochim 2002). It was then revised and translated into Chinese by the first author. The translated version was checked by another translator and a tutor in the course to confirm the accuracy of the translation and to avoid misunderstanding from the teachers' perspectives. Four items, one each from the attention, relevance, confidence, and effort scale, were deleted to ensure sufficient reliability (Cronbach's alpha larger than 0.7).

The mean inter-correlation of one scale with the other scales ranges from 0.38 to 0.57 . Though somewhat high, it is still worthwhile and meaningful to consider the scales independently, especially because the literature indicates that there could exist a pronounced response style among Chinese questionnaire respondents that might contribute to these intercorrelations. The influence of response style on scale intercorrelation is discussed more extensively in the conclusion section.

\section{Interviews}

We used a structured interview framework starting off with open questions and then gradually moving towards more specific issues, addressing the 11 aspects in the questionnaire scales in particular. Interviewees were asked to describe their perceptions on these, and also to explain the reasons behind their scores. Sample questions include:

1. Did you feel motivated during the course? At which moments did you feel motivated? What was the trigger of your motivation/frustration?

2. Describe your communication and cooperation with other teachers in this course in terms of form, frequency, and effectiveness. How did you feel about interaction and communication? What do you think were the reasons?

3. Have you applied what you learned in this course in your classroom? If yes, can you provide an example? How do you feel about this application? If not, why?

Each interview lasted for about 1 hour. All interviews were audiotaped with interviewees' permission and briefly transcribed by the first author.

\section{Data analysis}

Quantitative data were analyzed using descriptive statistics, simple correlation analysis, and multiple regression analysis. For answering the first research question, mean scores 
and standard deviations were computed for the 11 scales of the reaction level. Mean scores and standard deviations of the scales of learning, behavior, and results were computed to answer the second research question. Simple correlation analysis and multiple stepwise regression analyses were employed to explore associations between teachers' perceptions of the course and their perceptions of the training outcomes. Scales from the reaction section were used as independent variables; learning, behavior, and result were the dependent variables. Finally, simple correlation $(r)$, standardized regression coefficients $(\beta)$, multiple correlations $(R)$, and $R^{2}$ representing the amount of variance explained were calculated.

Qualitative data analysis included categorizing teachers' answers to the open-ended questions in the questionnaire survey and the interview results into major themes. The transcribed interview results were organized in a matrix with a row for each of the eight interviewees and a column for each of the aspects from the interviews/questionnaires. Finally, the interview results were summarized according to the scales in questionnaire survey. Interview transcripts were analyzed by the first author and outcomes were discussed with, verified and approved by the other two authors. Typical statements were selected and presented in the result section where relevant.

\section{Results}

\section{Teachers' perceptions of the course}

Table 4 shows the mean score and standard deviation for teachers' satisfaction with each aspect of the course. Next, each aspect is discussed by looking at both the questionnaire and the interview data.

The mean of $4.11(\mathrm{SD}=0.64)$ in Table 4 for the external support scale suggests that teachers generally felt supported by their external environment in participating in this course. Although the questionnaire result was very favorable, most interviewees stated that they felt neither supported nor unsupported by their external environment because this course was mandatory for them.

For motivation (attention, relevance, confidence, and effort), teachers reported positive attitudes towards the training on the questionnaire, but the interview results told a different story. Interviewees stated that they felt unmotivated during the course for three

Table 4 Means and standard deviations for teachers' perceptions of the course

\begin{tabular}{llll}
\hline Scale & $N$ & Mean & SD \\
\hline External support & 221 & 4.11 & 0.64 \\
Attention & 203 & 3.81 & 0.69 \\
Relevance & 209 & 3.87 & 0.68 \\
Confidence & 199 & 3.78 & 0.66 \\
Effort & 204 & 3.74 & 0.67 \\
Interaction & 215 & 3.03 & 0.73 \\
People & 217 & 4.06 & 0.97 \\
Platform & 191 & 4.05 & 0.82 \\
Structure & 197 & 4.05 & 0.80 \\
Content & 214 & 3.87 & 0.68 \\
Connection & 201 & 3.82 & 0.63 \\
\hline
\end{tabular}


main reasons. The first one related to the lack or unsuitability of ICT equipment. School $\mathrm{C}$ installed projectors in the classroom after this course, but teachers indicated they had no opportunity to practise with them during the training. Projectors and electronic whiteboards in other schools were defective and did not get repaired in time. The second reason was a lack of incentives during the training. Every 50 teachers got one tutor who was in charge of monitoring their learning progress, giving scores to their homework, and arranging online discussions. Interviewees stated that tutors just checked whether they had uploaded homework in time but did not check the quality of their work. The third cause involved personal reasons. One interviewee (F1) felt that he was too old to learn something new, had confidence in his teaching, and could not see the necessity of applying ICT in his classroom. In addition, some interviewees were extremely busy during the training period because of personal issues or extra workload. On the positive side, interviewees indicated that the content was a main factor for their motivation. They felt motivated because they found the training content useful and applicable. They perceived that the difficulty level of the training content also affected their motivation. One interviewee (F2) stated that the content was too easy for him, while another interviewee (F1) felt that the content was too difficult: "I didn't feel motivated during this course. It was a task for me, a part of my daily work".

A mean of $3.03(\mathrm{SD}=0.73)$ in Table 4 indicates that teachers felt that the frequency and effectiveness of the interaction during this course were appropriate. Within this scale, teachers reported the lowest score $($ Mean $=2.66$. $\mathrm{SD}=0.87$ ) for the frequency of their interaction with trainers. The follow-up interviews provided additional evidence on this issue. All interviewees indicated that the online interaction with trainers, with tutors, and among peer teachers was rare and ineffective. Interviewees felt that the 'question and answer' part with videos from experts was helpful, but they expected more direct and individualized interaction with their trainers. Interviewees indicated that tutors only sent them a message when they were behind in the learning schedule. All interviewees indicated that the online interaction among peers was rare and ineffective. Teachers left comments on each other's contributions as the course required, but most of these comments were superficial, which negatively affected the teachers' motivation to leave meaningful comments in return. Some interviewees (A2 \& F2) felt that reviewing comments of others could be helpful, especially those comments in which teachers shared practical experiences like merging ICT with teaching, and coping with students' varied levels of competence, etc. In addition, discussion with colleagues was theoretically expected to optimize the training outcomes. According to the interview results, only school A arranged two meetings to discuss the course, with the interviewee from school A confirming the benefit of these group discussions. Teachers from other schools learned individually.

With a mean of 4.05, teachers expressed satisfaction towards the people (trainer and tutor), the platform, and the structure of this course. The mean scores for content and connection with practice were slightly lower (around 3.85). According to the interviews, interviewees felt that the performance of the trainer and tutor in the course was neutral. They also had expected more-experienced teachers and ICT experts to be the trainers in this course, rather than professors from universities. Interviewees did not talk much about the platform, but they expressed satisfaction with the structure of the course. They liked the module instruction part, which helped them to gain an overview of the learning objectives and procedures. They also liked the content structure of each block, which contained not only a video lesson but also a video explaining how a lesson with ICT was designed, and why it was designed in that way. Speaking of the training content, most interviewees thought that there was too much content for a three-month course and also that it was too 
diverse, especially for a course about teaching with ICT. They indicated that they needed more time to learn ICT skills thoroughly and apply ICT in their own classrooms. They preferred more practical content and less theoretical content. Interviewees held different opinions about the connection between the course and their daily practice. Most interviewees felt that the ICT skills introduced in the course roughly matched their daily practice, but they stressed that these needed to be adapted more for application in their own context.

\section{Teachers' perceptions of the training outcomes}

This section presents teachers' perceptions of the training outcomes in terms of the learning, behavior, and results level of Kirkpatrick's evaluation model. A mean of 3.83 for the learning scale suggested that teachers confirmed a positive change in knowledge, skill, and attitude about teaching with ICT (see Table 5). The mean for behavior and results were slightly lower, which seems to echo with the above-mentioned difficulty of transferring skills learned into daily practice.

The follow-up interview provided more-detailed information about teachers' perceptions of training outcomes at the learning level. In general, interviewees found this course helpful, with the most-important influence of this course being that they now knew what they could do with ICT. At the same time, they perceived a relatively small increase in knowledge and skills because of the short duration of the learning course. Two interviewees stated that they held more-positive attitudes towards ICT after this course. They believed that ICT would optimize their teaching if they could learn further, and they indicated that they would keep learning in the future if needed.

Regarding behavior, all interviewees indicated that they only applied a little bit of what they learned in this course into their classroom for two reasons. The first personal reason was that two interviewees (F1 \& A2) indicated that they were used to working with chalk and the blackboard, and that they had done a good job without ICT for more than 20 years. Some other interviewees said that they felt that their ICT skills were not good enough to implement their ideas and that they still needed to learn more and practise more. The second set of reasons was external. Most interviewees said that they had problems with using ICT equipment in their school. In addition, using ICT in teaching was not encouraged by the principal or colleagues. Interviewees also felt that the classroom video lectures shown in the course originated from urban schools. In their view, the ICT tools and methods shown in the course were not applicable in their own classroom because of the difference between urban and rural schools.

In terms of the results level, teachers stated that they could hardly claim any effect in their practice that was attributable to this course. Their teaching practice had undergone no substantial change after this course. Interviewees stated that, at the beginning of using ICT, students were more motivated and active in the classroom, but that the positive effect reduced once students had become used to the new teaching approach. Interviewees also

Table 5 Means and standard deviations for teachers' perceptions of the training outcomes

\begin{tabular}{llll}
\hline Scale & $N$ & Mean & SD \\
\hline Learning & 205 & 3.83 & 0.60 \\
Behavior & 203 & 3.68 & 0.66 \\
Results & 207 & 3.71 & 0.69 \\
\hline
\end{tabular}


stated that they viewed teaching with ICT as a choice they had, and that they would choose to use ICT in the classroom when the lesson content could be better taught and learned with ICT. An example of this can be found in a statement from teacher B1:

In the beginning, students were attracted by the new approach. But the attractiveness reduced gradually after that. Teaching with ICT enables teachers to cover a lot of content in one lesson, but it is not suitable for every lesson of every subject. Using ICT is an approach to optimize teaching and learning, but not the final goal.

\section{Associations between teachers' perceptions of the course and training outcomes}

Associations between teachers' perceptions of the course and their perceptions of training outcomes were investigated using simple correlation analysis and multiple regression analysis. As shown in Table 6, the simple correlation analysis revealed that teachers' perceptions of all aspects of the course had statistically significant and positive associations with teachers' perceptions of the training outcomes in learning, behavior, and results. The simple correlation coefficients ranged from 0.42 to 0.76 , which indicated moderate to strong correlations. The multiple regression analysis indicates that the multiple correlation $(R)$ found between teachers' perceptions of the course and the training outcomes ranged from 0.82 to 0.83 , which indicates moderate associations between teachers' perceptions of the course and the training outcomes. The $R^{2}$ coefficient indicated that about $68 \%$ of the variance in teachers' perceptions of the behavior and results could be attributed to their perceptions of the course, while this percentage for the learning scale was $70 \%$. The analysis also showed that the connection scale contributed significantly to the variance in all three scales of training outcomes. In addition, the attention and relevance scales contributed significantly to the variance in the learning scale, the relevance and platform scales contributed significantly and positively to the variance in the behavior scale, and the confidence scale contributed significantly to the variance in the results scale. Not all variables contributed to a similar degree to the outcomes.

\section{Conclusion and discussion}

\section{General conclusion}

This study focused on teachers' perceptions of a Chinese online inservice teacher training course within the NTTP framework, and how it influenced teachers' perceptions of the training outcomes. Using a combination of data sources (questionnaire survey, and interviews), teachers' perception data and their explanations for these perceptions were obtained.

The questionnaire survey showed that teachers found this course helpful in general, while they felt less satisfied with their experience of motivation and interaction during the training. The results of learners generally being satisfied with an online course are supported by other research (Billings et al. 2001; Ryan et al. 1999; Tu and Mcissac 2010; Woo and Kimmick 2000). In follow-up interviews, teachers connected their lack of motivation to technical problems, lack of incentives, and personal reasons. Interviewees reported that their interaction with trainers, tutors, and other teachers was rare and ineffective. They also connected the poor interaction with their lack of motivation. Interviewees stated that they 


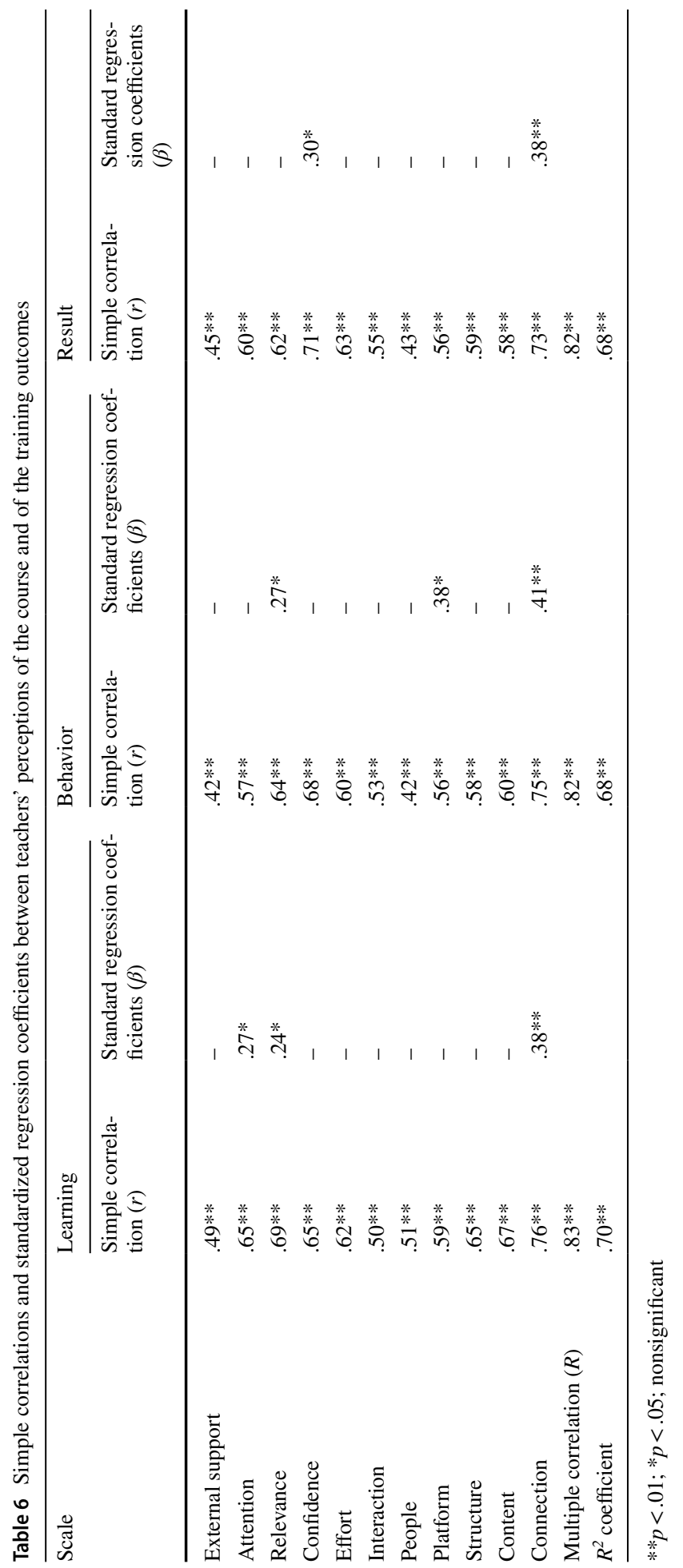


liked the part which was closely connected with their daily practice. Technical difficulties were given as a reason - even though not dominant - for low motivation, participation, and satisfaction in online training (Krammer et al. 2006). Interaction with other teachers and effective feedback from trainer and tutors are essential for teachers' positive perception of the effects of professional development courses (Hattie and Timperley 2007; van Veen et al. 2005). From the perspective of adult learning theory, Mason (2006) proposed that courses for inservice adults need to provide opportunities for them to articulate their own ideas, draw on their past experiences, and integrate learning with their jobs. One of the effective strategies is to encourage dialogue and discussions among adult learners during the training (Dobrovolny 2006).

China sits in the higher rankings of the Power Distance index in Hofstede's (2011) national cultural dimensions studies, suggesting that individuals are influenced by formal authority. Regarding the course investigated in this study, the course design did not enable direct interaction between trainer and teacher. Teachers' interaction with tutors was limited to reminders of training progress according to the interviews. Despite all of this, teachers reported satisfaction on the survey's people scale and interviewees spoke well of trainer and tutors performance. These findings might in part be linked to the high power distance orientation in Chinese culture, with teachers being less likely to criticize the performance of the authority group.

China is also regarded as a highly collectivist culture in which people act in the interests of the group and not necessarily of themselves. In this study, teachers did not participate in this course voluntarily. The collective participation was compulsory for teachers in the six schools chosen by local educational authority. According to the questionnaire survey and confirmed by the interviews, teachers accepted this course as a part of their duty but, at the same time, this might have led to a lack of intrinsic motivation for the training. The collectivist orientation might also have contributed to the perceptions of rather superficial interaction; perhaps teachers were hesitant to provide feedback or critique to comments by other teachers. Future research, however, is needed to provide further support for these interpretations.

Teachers indicated that their knowledge and attitude about teaching with ICT had improved, but that changes in teaching practice and students' achievement were limited. This is in line with the work of Clarke and Hollingsworth (2002) who identified that the learning of teachers can occur in different domains and that changes in teachers' knowledge might not necessarily lead to changes in teachers' practice. Some other studies that applied Kirkpatrick's model also reported limited growth at the behavior and results level (Strother 2002). Interviewees indicated that they accumulated knowledge from this course, but struggled with application in their classroom. Reasons for the lack of application included technical problems (the equipment in school lacked maintenance), lack of adaptation (the content in this course was not adaptable in their classroom), and personal reasons. These findings are in line with review studies on predictive factors of training transfer (Blume et al. 2016; Burke and Hutchins 2007; Cheng and Hampson 2008).

Teachers' perceptions of the course were significantly correlated with teachers' perceptions of training outcomes. This is in line with prior studies suggesting the influence of learners' satisfaction on perceived learning outcomes (Ruona et al. 2002; Eom et al. 2006; Tan et al. 2003). Teachers' perceptions of the connection between the course and their daily practice contributed most to the variance in their perceptions of training outcomes. An investigation of secondary-school teachers' perceptions of interactive whiteboard training workshops in Taiwan highlighted that teachers raised their motivation when experienced teachers shared whiteboard teaching strategies (Lai 2010). Sharing such strategies 
is a perfect example of content that is connected to teachers' daily practice. A review by Bhatti and Kaur (2010) suggested that participants' perceptions of how content related to actual job tasks affects participants' motivation to transfer new learning. The emphasized contribution of connection to perceived training outcomes can somehow also be an attribute of the Chinese context. According to Hofstede's national cultural dimensions studies, China has a comparatively higher score on the Longterm Orientation dimension, suggesting that China has a very pragmatic culture. The questionnaire survey and interviews both indicated that Chinese teachers viewed connection, or the possibility of transferring in practice, as the most important factor for their perceived training outcomes.

Questionnaire and interviews results complemented each other well, but also highlighted some differences. Teachers reported high average scores on all 11 questionnaire scales, while the interviews revealed that they felt unsatisfied with some aspects of the course, especially interaction and motivation during training. A possible explanation for this phenomenon is provided by response style theory. Response styles are respondents' tendencies, for example, to select specific options disproportionately in favor of the positive side (acquiescence response style or ARS) or the middle of the scale (midpoint response style or MRS; Stening and Everett 1984). Many studies highlight the connection between response style and cultural differences (Chen et al. 2016; de Jong et al. 2008; Johnson 2005; Van Herk et al. 2004). Chinese are assumed to have relatively higher MRS and ARS (Harzing 2006), suggesting that respondents might have an inclination to give a higher score than their actual perceptions; our results certainly align with this. The response style of Chinese teachers might also explain the relatively high intercorrelations between the scales. When teachers tend to choose positive or mid-point responses, intercorrelations could be high. Furthermore, different modes of data collection lead to differences in response style (Vaerenbergh and Thomas 2012). However, interviewees in the present study were more critical to the online course and to the learning outcomes in interviews, especially when the interviewer asked detailed questions. This finding contradicts previous research, which revealed that telephone surveys (as with interviews in the present study) lead to higher ARS than face-to-face, paper-and-pencil surveys (as with questionnaire surveys in the present study) (Weijters et al. 2008). This disagreement might also be attributed to the unique Chinese context, although there is a lack of empirical research to confirm this hypothesis.

\section{Limitations and suggestions for future research}

This study involved a sample of all teachers from one district to investigate the influence of an online course on a group of teachers. The representativeness of this study is thus limited. Ideally, when evaluating training outcomes, changes in teachers' knowledge, teaching practice, and students' achievement should be made visible via observation, asking students' perceptions, and conducting measurements prior to and after the course. However, because of limitations in time and resources, we used teachers' self-reported perceptions to reveal the training outcomes.

Despite the limitations stated above, this study provided a needed glimpse into ongoing online teacher courses in China and research on learner's perceptions in online learning environment. In general, similar factors emerged as important in this study as they did in Western studies; however, combining interview data with questionnaire data shows a more nuanced picture. Thus, our study shows the need to adapt evaluation methods to the specific cultural context. Furthermore, longitudinal research is necessary to uncover the 
role of in-service courses in teachers' professional development. Data concerning teachers' changes at the learning, behavior, and results level are needed. More research on the interaction is needed to reveal the reasons for, and to find a solution for, the rare and ineffective interaction on the online platform.

\section{Implications}

Questionnaire results revealed that the connection between the course content and teachers' practice contributed most to training outcomes. Interviewees also indicated that the adaptability of training content affected both their motivation to learn during training and motivation to practise after training. Base on this, the course design should be adapted to teachers in at least two ways. First, this course provided elective courses and enabled teachers with freedom in choosing learning topics. Future courses should provide comprehensive elective course resources to cover different topics and different degrees of difficulty to meet teachers' individual training needs. This is of particular significance for a course focusing on ICT competence with collective participation because teachers' previous ICT competence could vary a lot.

Second, the ICT equipment in school and teachers' learning needs should be investigated in advance. Participating in a course about teaching with ICT when the school has not installed relevant ICT equipment in the classroom (projector and/or electronic whiteboard) certainly reduces teachers' satisfaction and the expected training outcomes. The local education department should be sure that teachers have enough ICT equipment in schools (ICT equipment in the classroom for practice and in teachers' offices for learning) before implementing a course about teaching with ICT. The school should maintain the equipment in the classroom and make sure that they can be repaired in time in case of malfunctioning.

Third, teachers' interactions with trainers, tutors, and other teachers during courses need enhancement. Online environments can accommodate large numbers of teachers from the same district and/or teaching the same subject in a course, and also can enable varied possibilities of online interaction. The current study revealed that teachers were not satisfied with the frequency and effectiveness of interaction during training and that much can be improved in this respect. Future courses should emphasize and encourage interactions.

Finally, teacher professional development is a lifelong effort. Changes in teachers' behavior and students' achievement happen gradually. According to the interview results, more extended training about teaching with ICT is necessary and would be welcome.

\section{Appendix}

\section{Questionnaire}

\section{Background}

1. Your gender: $\square$ Male $\square$ Female.

2. Your age: 
3. Teaching subject:

$\square$ Chinese $\square$ Mathematics $\square$ English $\square$ Physics $\square$ Chemistry $\square$ Biology $\square$ Civil $\square$ History.

$\square$ Geography $\square$ Physical Education $\square$ Art $\square$ Music $\square$ ICT $\square$ Integrated Practice $\square$ Other.

4. Your teaching experience: ___ (year).

5. Your current professional title:

$\square$ Senior $\square$ Intermediate $\square$ Junior.

\section{Your highest record of schooling:}

$\square$ Master and above $\square$ Bachelor $\square$ Associate degree $\square$ Below than associate degree.

\section{Your role in school (multiple options possible):}

School manage group $\square$ Subject head $\square$ Mentor $\square$ Subject teacher $\square$ Others (please specify).

\section{Each classroom in your school has (multiple options possible):}

$\square$ TV $\square$ DVD player $\square$ Multimedia projector $\square$ Electronic whiteboard.

9. Number of multi-media classrooms in your school:

10. The equipment in the multimedia classrooms include (multiple options possible):

$\square$ TV $\square$ DVD player $\square$ Multimedia projector $\square$ Electronic whiteboard $\square$ Computer for each student.

$\square$ Electronical Monitoring System $\square$ Other (please specify:

\section{At home you have (multiple options possible):}

$\square$ Computer $\square$ Internet connection $\square$ Tablet $\square$ Smart phone.

How did your principal, colleagues and family perceive your participation in this course?

\begin{tabular}{|c|c|c|c|c|}
\hline $\begin{array}{l}\text { Strongly dis- } \\
\text { courage }\end{array}$ & Discourage & Neutral & Encourage & $\begin{array}{l}\text { Strongly } \\
\text { encour- } \\
\text { age }\end{array}$ \\
\hline
\end{tabular}

The principal

Colleagues

Family 


\section{Motivation}

\section{According to your experience in participating in this training course, please select one} that fits your perceptions best:

\section{I like this training course}

If I am honest, I would prefer not to participate in this course

I enjoyed working on assignments in this course

Online training will easily become a hobby of mine

In my later career I need what I learned in this course

I don't think participating in this course is of much use

The major part of what I learned from this course is of use in my daily work

Participating in this course is important for my professional development

I did pretty good in this course

Usually, I understand what is being told during the training activities in this course

I can understand extra materials provided in this course

Somehow I could not understand training activities in this course

I refused to devote much free time in this course

Training activities in this course are usually very interesting

It was of interest to me what was been told during this course

I did put in more energy than required in this course

\section{Interaction}

14. Which option best describes the frequency of your interaction with trainer, tutor, and other teachers during the training course?

\begin{tabular}{|c|c|c|c|c|c|}
\hline & Very rare & Rare & Neutral & Frequent & Very frequent \\
\hline \multicolumn{6}{|l|}{ With trainer } \\
\hline \multicolumn{6}{|l|}{ With tutor } \\
\hline With other teachers & & & & & \\
\hline
\end{tabular}

15. Which option best describes the effectiveness of your interaction with trainer, tutor, and other teachers during the training course? 


\begin{tabular}{lllll}
\hline Very ineffective & Ineffective & Neutral & Effective & Very effective \\
\hline
\end{tabular}

With trainer

With tutor

With other teachers

\section{Satisfaction}

16. Please rate the following aspects of this training course:

\begin{tabular}{|c|c|c|c|c|c|}
\hline & Very poor & Poor & Neutral & Good & Excellent \\
\hline \multicolumn{6}{|l|}{ Trainers' performance } \\
\hline \multicolumn{6}{|l|}{ Tutor's performance } \\
\hline \multicolumn{6}{|l|}{ Navigation in this platform } \\
\hline \multicolumn{6}{|l|}{ Layout in this platform } \\
\hline \multicolumn{6}{|l|}{ Problem solving system (e.g. technical support) } \\
\hline \multicolumn{6}{|l|}{ Operation manual } \\
\hline \multicolumn{6}{|l|}{ Variety of teacher-learning activities } \\
\hline \multicolumn{6}{|l|}{ Trainee assessment plan } \\
\hline \multicolumn{6}{|l|}{ Coherence among activities } \\
\hline \multicolumn{6}{|l|}{ Monitoring system } \\
\hline \multicolumn{6}{|l|}{ Opportunities for active learning } \\
\hline \multicolumn{6}{|l|}{ Opportunities for trainer-trainee interaction } \\
\hline \multicolumn{6}{|l|}{ Opportunities for tutor-trainee interaction } \\
\hline \multicolumn{6}{|l|}{ Opportunities for trainee-trainee interaction } \\
\hline \multicolumn{6}{|l|}{ Opportunities for cooperating with other trainees } \\
\hline \multicolumn{6}{|l|}{ Freedom in choosing lessons } \\
\hline \multicolumn{6}{|l|}{ Freedom in arrange individual learning plan } \\
\hline Course management & & & & & \\
\hline
\end{tabular}

17. To what extent do you agree that:

Strongly Disagree Neutral Agree Strongly agree disagree

The course meets my expectations

The whole course was well planed

The course was designed for my teaching subject

The course was designed for secondary teachers

The course was designed to fit teachers in my province

The lecture content is clear

The lecture content is sufficient

Case studies in this course suit my situation

I am clear about the goal of this course

The course focuses on my daily practice 
Strongly Disagree Neutral Agree Strongly agree disagree

This course focused on knowledge in teaching with

ICT

This course focused on skill in teaching with ICT

\section{Training outcomes}

After this course, to what extent do you agree that:

Strongly Disagree Neutral Agree Strongly agree disagree

I know more software about teaching with ICT

I know more about when to use ICT in my teaching

I know more about why use ICT in my teaching

I know more about how to use ICT in my classroom

My confidence in using ICT has improved

I have more faith in teaching with ICT

I feel more positive toward the result of teaching with ICT

I like my job more

I feel more confident in my work

I use more ICT to support lesson preparation

I use more ICT in my teaching

I use more ICT in my class management

I use more ICT in students assessment

I use more ICT in my cooperation with colleagues

I use more ICT in my daily life

My students' motivation in learning has improved

My students became more active in classroom

My students' learning achievement improved

I can contribute more to my school development

\section{Suggestions:}

\section{What would you suggest to improve an online teacher training course (e.g. training content, trainer, interaction, platform, etc.)?}

Acknowledgements This research project was funded by the Chinese Scholarship Council.

Open Access This article is licensed under a Creative Commons Attribution 4.0 International License, which permits use, sharing, adaptation, distribution and reproduction in any medium or format, as long 
as you give appropriate credit to the original author(s) and the source, provide a link to the Creative Commons licence, and indicate if changes were made. The images or other third party material in this article are included in the article's Creative Commons licence, unless indicated otherwise in a credit line to the material. If material is not included in the article's Creative Commons licence and your intended use is not permitted by statutory regulation or exceeds the permitted use, you will need to obtain permission directly from the copyright holder. To view a copy of this licence, visit http://creativecommons.org/licenses/by/4.0/.

\section{References}

Allen, D., \& Fraser, B. J. (2007). Parent and student perceptions of classroom learning environment and its association with student outcomes. Learning Environments Research, 10(1), 67-82.

Arbaugh, J. B. (2000). Virtual classroom characteristics and student satisfaction with Internet-based MBA courses. Journal of Management Education, 24(1), 32-54. https://doi.org/10.1177/10525 6290002400104.

Bhatti, M. A., \& Kaur, S. (2010). The role of individual and training design factors on training transfer. Journal of European Industrial Training, 34(7), 656-672. https://doi.org/10.1108/0309059101 1070770 .

Billings, D. M., Connors, H. R., \& Skiba, D. J. (2001). Benchmarking best practices in web-based nursing courses. Advances in Nursing Science, 23(3), 41-52.

Blume, B. D., Ford, J. K., Baldwin, T. T., \& Huang, J. L. (2016). Transfer of training: A meta-analytic review. Journal of Management, 36(4), 1065-1105. https://doi.org/10.1177/0149206309352880.

Bonem, E. M., Fedesco, H. N., \& Zissimopoulos, A. N. (2020). What you do is less important than how you do it: The effects of learning environment on student outcomes. Learning Environments Research, 23(1), 27-44.

https://doi-org.ezproxy2.utwente.nl/10.1007/s10984-019-09289-8

Burke, L. A., \& Hutchins, H. M. (2007). Training transfer: An integrative literature review. Human Resource Development Review, 6(3), 263-296. https://doi.org/10.1177/1534484307303035.

Chandra, V., \& Fisher, D. L. (2009). Students' perceptions of a blended web-based learning environment. Learning Environments Research, 12(1), 31-44. https://doi.org/10.1007/s10984-008-9051-6.

Chen, C., Lee, S., Stevenson, H. W., Chen, C., Lee, S., \& Stevenson, H. W. (2016). Response style and cross-cultural comparisons of rating scales among East Asian and North American students. Phychological Science, 6(3), 170-175.

Cheng, E. W. L., \& Hampson, I. (2008). Transfer of training: A review and new insights. International Journal of Management Reviews, 10(4), 327-341. https://doi.org/10.1111/j.1468-2370.2007.00230.x.

Choi, T. H. (2013). Autobiographical reflections for teacher professional learning. Professional Development in Education, 39(5), 822-840. https://doi.org/10.1080/19415257.2012.737355.

Clarke, D., \& Hollingsworth, H. (2002). Elaborating a model of teacher professional growth. Teaching and Teacher Education, 18(8), 947-967. https://doi.org/10.1016/S0742-051X(02)00053-7.

Cox, M. (2000). What factors support or prevent teachers from using ICT in their classroom? Paper presented at British Educational Research Association annual conference. http://www.leeds.ac.uk/educol/ documents/00001304.htm. Accessed 22 June 2020

Cox, M., Webb, M., Abbott, C., \& Blakeley, B. (2003). A review of the research literature relating to ICT and attainment. London: Becta. Retrieved 22 June 2020, from http://dera.ioe.ac.uk/1600/1/becta_ 2003_attainmentreview_queensprinter.pdf.

de Jong, M. G., Steenkamp, J.-B.E., Fox, J.-P., \& Baumgartner, H. (2008). Using item response theory to measure extreme response style in marketing research: A global investigation. Journal of Marketing Research, 45(1), 104-115. https://doi.org/10.1509/jmkr.45.1.104.

Dobrovolny, J. (2006). How adults learn from self-paced, technology-based corporate training: New focus for learners, new focus for designers. Distance Education, 27(2), 155-170. https://doi.org/10.1080/ 01587910600789506.

Dorman, P. (2001). Associations between classroom environment and academic efficacy. Learning Environments Research, 4(3), 243-257.

Earle, J. E., \& Fraser, B. J. (2017). Evaluating online resources in terms of learning environment and student attitudes in middle-grade mathematics classes. Learning Environments Research, 20(3), 339-364. https://doi.org/10.1007/s10984-016-9221-x. 
Eom, S. B., Wen, H. J., \& Ashill, N. (2006). The determinants of students' perceived learning outcomes and satisfaction in university online education: An empirical investigation. International Journal of Global Management Studies, 4(2), 215-235. https://doi.org/10.1111/j.1540-4609.2006.00114.x.

Ertmer, P. A., \& Ottenbreit-Leftwich, A. T. (2010). Teacher technology change: How knowledge, confidence, beliefs, and culture intersect. Journal of Research on Technology in Education, 42(3), 255-284. https://doi.org/10.1080/15391523.2010.10782551.

Finsterwald, M., Wagner, P., Schober, B., Lüftenegger, M., \& Spiel, C. (2013). Fostering lifelong learningEvaluation of a teacher education program for professional teachers. Teaching and Teacher Education, 29, 144-155. https://doi.org/10.1016/j.tate.2012.08.009.

Frye, A. W., \& Hemmer, P. A. (2012). Program evaluation models and related theories: AMEE guide no 67. Medical Teacher, 34(5), 288-299. https://doi.org/10.3109/0142159X.2012.668637.

Garet, M., \& Porter, A. (2001). What makes professional development effective? Results from a national sample of teachers. American Educational Research Journal, 38(4), 915-945. https://doi.org/10.3102/ 00028312038004915.

Gilbert, M. C., Musu-Gillette, L. E., Woolley, M. E., et al. (2014). Student perceptions of the classroom environment: Relations to motivation and achievement in mathematics. Learning Environments Research, 17(2), 287-304.

Goktas, Y., Yildirim, Z., \& Yildirim, S. (2008). A review of ICT related courses in pre-service teacher education programs. Asia Pacific Education Review, 9(2), 168-179. https://doi.org/10.1007/BF03026497.

Guskey, T. (2002). Professional development and teacher change. Teachers and Teaching: Theory and Practice, 8(3), 381-391.

Harzing, A.-W. (2006). Response styles in cross-national survey research: A 26-country study. International Journal of Cross Cultural Management, 6(2), 243-266. https://doi.org/10.1177/1470595806066332.

Hattie, J., \& Timperley, H. (2007). The power of feedback [transfer argument]. Review of Educational Research, 77(1), 81-112. https://doi.org/10.3102/003465430298487.

Hofstede, G. (2011). Dimensionalizing cultures: The Hofstede model in context. Online Readings in Psychology and Culture, 2(1), 1-26. https://doi.org/10.9707/2307-0919.1014.

Hong, K. S. (2002). Relationships between students' and instructional variables with satisfaction and learning from a Web-based course. Internet and Higher Education, 5(3), 267-281. https://doi.org/10.1016/ S1096-7516(02)00105-7.

House, T. C. (2000). A case study of Chinese students' attitudes toward their first online learning experience. Educational Technology Research and Development, 51(3), 95-102.

Hunzicker, J. (2011). Effective professional development for teachers: A checklist. Professional Development in Education, 37(2), 177-179. https://doi.org/10.1080/19415257.2010.523955.

Johnson, T. (2005). The relation between culture and response styles: Evidence from 19 countries. Journal of Cross-Cultural Psychology, 36(2), 264-277. https://doi.org/10.1177/0022022104272905.

Jung, I. (2001). Issues and challenges of providing online inservice teacher training: Korea's experience objectives of this case study. International Review of Research in Open and Distance Learning, 2(1), $1-18$.

Jung, I. (2005a). Cost-effectiveness of online teacher training. Open Learning, 20(2), 131-146. https://doi. org/10.1080/02680510500094140.

Jung, I. (2005b). ICT-pedagogy integration in teacher training: Application cases worldwide. Educational Technology and Society, 8(2), 94-101.

Keller, J. (2000). How to integrate learner motivation planning into lesson planning: The ARCS model approach. Santiago: Paper presented at VII Semenario Internationale.

Keller, J. M. (1987). Development and use of the ARCS model of instructional de-sign. Journal of Instructional Development, 10(3), 2-10.

Kennedy, P. (2002). Learning cultures and learning styles: Myth-understandings about adult (Hong Kong) Chinese learners. International Journal of Lifelong Education, 21(5), 430-445. https://doi.org/10. 1080/02601370210156745.

Khalil, M., \& Saar, V. (2009). The classroom learning environment as perceived by students in Arab elementary schools. Learning Environments Research, 12(2), 143-156.

Kirkpatrick, D. L. (1970). Evaluation of training. In P. L. Browning (Ed.), Evaluation of short-term training in rehabilitation (pp. 35-56). Eugene: College of Education Department of Special Education, University of Oregon.

Kirkpatrick, D. L., \& Kirkpatrick, J. D. (2005). The four levels in the 21 st century. In D. L. Kirkpatrick \& J. D. Kirkpatrick (Eds.), Transferring learning to behavior: Using the four levels to improve performance (pp. 3-9). San Francisco: Berrett-Koehler Publishers. 
Krammer, K., Ratzka, N., Klieme, E., Lipowsky, F., Pauli, C., \& Reusser, K. (2006). Learning with classroom videos: Conception and first results of an online teacher-training program. Zeitschrift für Didaktik der Mathematik, 38(5), 422-432. https://doi.org/10.1007/BF02652803.

Lai, H. (2010). Secondary school teachers' perceptions of interactive whiteboard training workshops: A case study from facilitating pedagogical practices through IWBs. Australasian Journal of Educational Technology, 26(4), 511-522.

Li, N. (2020). Analyzing online in-service teacher training courses in China. Unpublished doctoral dissertation. Eindhoven: ESoE, Eindhoven University of Technology.

Long, L. K., DuBois, C. Z., \& Faley, R. H. (2008). Online training: The value of capturing trainee reactions. Journal of Workplace Learning, 20(1), 21-37. https://doi.org/10.1108/MRR-09-2015-0216.

Magen-Nagar, N., \& Steinberger, P. (2017). Characteristics of an innovative learning environment according to students' perceptions: Actual versus preferred. Learning Environments Research, 20(3), 307-323. https://doi.org/10.1007/s10984-017-9232-2.

Mason, R. (2006). Learning technologies for adult continuing education. Studies in Continuing Education, 28(2), 121-133. https://doi.org/10.1080/01580370600751039.

Mumtaz, S. (2000). Factors affecting teachers' use of information and communications technology: A review of the literature. Journal of Information Techology for Teacher Education, 9(3), 319-342. https://doi.org/10.1080/14759390000200096.

Omar, M., Gerein, N., Tarin, E., Butcher, C., Pearson, S., \& Heidari, G. (2009). Training evaluation: A case study of training Iranian health managers. Human Resources for Health, 7(1), 1-14. https://doi.org/10. 1186/1478-4491-7-20.

Penuel, W. R., Fishman, B. J., Yamaguchi, R., \& Gallagher, L. P. (2007). What makes professional development effective? Strategies that foster curriculum implementation. American Educational Research Journal, 44(4), 921-958. https://doi.org/10.3102/0002831207308221.

Piccoli, G., Ahmad, R., \& Ives, B. (2001). Web-based virtual learning environments: A research framework and a preliminary assessment of effectiveness in basic it skills training. MIS Quarterly, 25(4), 401-426. https://doi.org/10.2307/3250989.

Praslova, L. (2010). Adaptation of Kirkpatrick's four level model of training criteria to assessment of learning outcomes and program evaluation in Higher Education. Educational Assessment, Evaluation and Accountability, 22(3), 215-225. https://doi.org/10.1007/s11092-010-9098-7.

Qu, Y. (2012). Xinjiang Corps National Training Plan: Short-Term Concentration of Investigation on the Situation and Countermeasures. Shihezi: Shihezi University.

Rajeev, P., Madan, M., \& Jayarajan, K. (2009). Revisiting kirkpatrick's model-An evaluation of an academic training course. Current Science, 96(2), 272-276.

Robinson, B. (2008). Using distance education and ICT to improve access, equity and the quality in rural teachers' professional development in Western China. International Review of Research in Open and Distance Learning, 9(1), 1-17.

Ruona, W. E. A., Leimbach, M., Holton, E. F., III., \& Bates, R. (2002). The relationship between learner utility reactions and predicted learning transfer among trainees. International Journal of Training and Development, 6(4), 218-228. https://doi.org/10.1111/1468-2419.00160.

Ryan, M., Carlton, K. H., \& Ali, N. S. (1999). Evaluation of traditional classroom teaching methods versus course delivery via the World Wide Web. Journal of Nursing Edu-cation, 38(6), 272-277.

Seet, L. Y. B., \& Quek, C. L. (2010). Evaluating students' perceptions and attitudes toward computer-mediated project-based learning environment: A case study. Learning Environments Research, 13(2), 173185. https://doi.org/10.1007/s10984-010-9073-8.

Stening, B. W., \& Everett, J. E. (1984). Response styles in a cross-cultural managerial study. Journal of Social Psychology, 122, 151-156.

Strother, J. (2002). An assessment of the effectiveness of e-learning in corporate training programs. International Review of Research in Open and Distance Learning, 3(1), 1-17.

Sun, P. C., Tsai, R. J., Finger, G., Chen, Y. Y., \& Yeh, D. (2008). What drives a successful e-Learning? An empirical investigation of the critical factors influencing learner satisfaction. Computers and Education, 50(4), 1183-1202. https://doi.org/10.1016/j.compedu.2006.11.007.

Tamkin, P., Yarnall, J., \& Kerrin, M. (2002). Kirkpatrick and Beyond: A Review of Models of Training Evaluation. Brighton: The Instituye for Employment Studies.

Tana, J., Hall, R. J., \& Boyce, C. (2003). The role of employee reactions in predicting training effectiveness. Human Resource Development Quarterly, 14(4), 397-411. https://doi.org/10.1002/hrdq.1076.

Trochim, W. M. K. (2002). The research methods knowledge base. William MK Trochim. https://doi.org/10. 2471/BLT.05.029181.

Tu, C., \& Mcissac, M. (2010). The relationship of social presence and interaction in on-line classes. Communication, 16(3), 131-150. 
UNESCO. (2002). Information and communication technology in education: A curriculum for schools and programme of teacher development. France: UNESCO.

Vaerenbergh, Y. V., \& Thomas, T. (2012). Response styles in survey research: A literature review of antecedents, consequences, and remedies. International Journal of Public Opinion, 25(2), 195-217.

Van Bruggen, J. (2005). Theory and practice of online learning. British Journal of Educa-tional Technology, 36(1), 111-112.

van DrielMeirink, J. H. J., van Veen, K., \& Zwart, R. C. (2012). Current trends and missing links in studies on teacher professional development in science education: A review of design features and quality of research. Studies in Science Education, 48(2), 129-160. https://doi.org/10.1080/03057267.2012. 738020 .

van Herk, H., Poortinga, Y. H., \& Verhallen, T. M. M. (2004). Response styles in rating scales: Evidence of method bias in data from six EU countries. Journal of Cross-Cultural Psychology, 35(3), 346-360. https://doi.org/10.1177/0022022104264126.

van Veen, K., Sleegers, P., \& van de Ven, P. H. (2005). One teacher's identity, emotions, and commitment to change: A case study into the cognitive-affective processes of a secondary school teacher in the context of reforms. Teaching and Teacher Education, 21(8), 917-934. https://doi.org/10.1016/j.tate.2005.06. 004.

Webster, B. J., \& Fisher, D. L. (2003). School-level environment and student outcomes in mathematics. Learning Environments Research, 6, 309-326.

Weijters, B., Schillewaert, N., \& Geuens, M. (2008). Assessing response styles across modes of data collection. Journal of the Academy of Marketing Science, 36(3), 409-422. https://doi.org/10.1007/ s11747-007-0077-6.

Woo, M., \& Kimmick, J. (2000). Comparison of internet versus lecture instruction methods for teaching nursing research. Journal of Professional Nursing, 16(3), 132-139.

Zhang, N. (2012). The theory and practice of research on the quality assessment of primary and secondary school teachers' national training program. Chongqing: Southwest University.

Publisher's Note Springer Nature remains neutral with regard to jurisdictional claims in published maps and institutional affiliations. 